\title{
A pharmacovigilance study in patients of chronic non-infective respiratory diseases attending outpatient department of pulmonary medicine in a tertiary care teaching hospital
}

\author{
Sanket S. Gaidhane*, Akash A. Khobragade, Abhijeet Joshi, \\ Monisha S. Chavan, Likith H. V., Akshay A. Chaware
}

Department of Pharmacology, GGMC and Sir JJ Group of Hospitals, Mumbai, Maharashtra, India

Received: 13 April 2021

Accepted: 05 May 2021

*Correspondence:

Dr. Sanket S. Gaidhane,

Email: Sanket.2339@gmail.com

Copyright: (c) the author(s), publisher and licensee Medip Academy. This is an open-access article distributed under the terms of the Creative Commons Attribution Non-Commercial License, which permits unrestricted non-commercial use, distribution, and reproduction in any medium, provided the original work is properly cited.

\begin{abstract}
Background: Adverse drug reactions (ADR) are the known dangers of any medicinal therapy. They are not only responsible for increasing the mortality and morbidity but also for multiplying the health care expenditure. It is important to monitor the adverse effects of the drugs in the patients on treatment for chronic non-infective respiratory diseases attending OPD of pulmonary medicine in a tertiary care teaching hospital

Methods: The study was single-centric, non-randomized and observational hospital-based study which was carried out for a period of 1 and a half years in JJ Hospital. The patients who were included in the study suffered from either of the 4 diseases-Chronic obstructive pulmonary disease (COPD), asthma, bronchiectasis or interstitial lung diseases (ILD). Data were analyzed by using Microsoft excel sheet. Based on the outcome of modified Hartwig and Siegel severity assessment scale, ADRs were grouped into various severity categories.

Results: One hundred and thirty-two number of ADRs were seen in 69 out of 352 patients (19.6\%) of the study population. The occurrence of ADR was found slightly higher in males i.e., 53.62\% as compared to females i.e., $46.38 \%$. The patients who were on treatment for ILD showed highest percentage of ADRs i.e., 57.89\% which is followed by bronchiectasis $(17.39 \%)$, COPD (16.17\%) and lastly asthma (10.26\%). The ADRs belonging to GIT system were highest in number i.e., 80. The most frequently occurring ADR in the study was palpitation which occurred in 14 cases i.e., 20.29\%. Out of 132 ADRs observed, 96 i.e., $72.73 \%$ belonged to the mild category and 36 ADRs i.e., 27.27\% belonged to the moderate category. Not a single severe ADR was found in the study.

Conclusions: It was found that $19.6 \%$ of the patient population suffered from ADRs, which is a considerable number. It is essential that health care professionals should support ADR monitoring process for the safety of the medicinal product. Proper implementation of ADR monitoring will help to reduce the harmful effects by early detection of drug safety problems in patients, assessing the risk-benefit in an individual and the population, improving the selection, rational use of drugs through the provision of timely warning to healthcare professionals.
\end{abstract}

Keywords: ADR, COPD, Asthma, Bronchiectasis, ILD, Modified Hartwig and Siegel severity assessment scale

\section{INTRODUCTION}

Chronic respiratory diseases are one of the major causes of morbidity and mortality in the global population. ${ }^{1}$ Chronic respiratory diseases can be divided into infective and noninfective diseases. Chronic infective respiratory diseases include diseases like tuberculosis, viral pneumonia like
H1N1 pneumonia, bacterial pneumonia like legionnaires pneumonia, etc. while diseases like chronic obstructive pulmonary disease, asthma, bronchiectasis, ILD, etc. can be classified as chronic non-infective respiratory diseases (CNIRD). Chronic non-infective respiratory diseases are amongst the commonly encountered diseases in the pulmonary OPD. ${ }^{2}$ 
The focus of our study will be on the four CNIRD diseases: COPD, asthma, bronchiectasis and ILD. The pathology underlying each of these diseases is different and chronicity adds to the problem. To treat the underlying pathology and to simultaneously relieve a variety of symptoms that the patients present with, it becomes mandatory to prescribe multiple medications to many patients, leading to polypharmacy. The common drugs used are inhaled corticosteroids, bronchodilators (like beta agonists and anticholinergics), oral theophylline, $\mathrm{N}$-acetyl cysteine, cough expectorants and the cough suppressants, etc. $^{3}$

ADR are the known dangers of any medicinal therapy. World health organisation (WHO) defines an ADR as "a response to a drug which is noxious and unintended and which occurs at doses normally used in man for prophylaxis, diagnosis or therapy for the disease and modification of function excluding failure to accomplish the intended purpose". 4

Adverse drug reaction is considered to be the sixth leading cause of death worldwide. It is estimated that almost $2 \%$ of hospital admissions are because of ADRs. Deaths due to drugs are estimated to be $0.17 \%$ in all medical patients. ADRs not only increase the mortality and morbidity but also multiply the health care cost. ${ }^{5}$ ADR monitoring is primarily essential for drugs with a narrow therapeutic index. $^{6}$

It is of prime importance to identify ADRs and to establish a causal relationship between the adverse event and the drugs used. It is preferable that ADRs should be assessed objectively and introduced based on an acceptable "probability scale".

ADRs accounts for significant morbidity, mortality and increased health care cost in the patient population. It is essential to monitor the adverse effects of various medications so that steps could be taken in the future to modify the treatment therapy and prevent the occurrence of such events.

The present study aims at monitoring the adverse effects of the drugs in the patients on treatment for chronic noninfective respiratory diseases attending OPD of pulmonary medicine in a tertiary care teaching hospital.

\section{METHODS}

The study was single-centric, non-randomized and observational hospital-based study which was carried out for a period of 1 and a half years after taking permission from institutional ethics committee (IEC). It was conducted in the department of pharmacology in collaboration with pulmonary medicine outpatient department in tertiary health care hospital.

Khan et al in their article titled "Causality assessment of adverse drug reaction in pulmonology department of a tertiary care hospital" estimated that ADR incidence was $32.23 \% .^{1,2}$ Using Lwanga and Lemeshow's sample size determination in health studies, WHO, 1991, sample size was calculated using the formula for single proportion using absolute specified proportion.

$\mathrm{n}=\mathrm{Z}^{2} 1-/ 2 \mathrm{P}(1-\mathrm{P}) / \mathrm{d}^{2}$

where $\mathrm{Z}=$ Standard normal deviate for (two sided, $95 \%)=1.96, \mathrm{P}=32.33 \%$ or $32.33, \mathrm{~d}=5 \%$ or 0.05

Calculated sample size works out to be 335 . With an expected attrition of $5 \%$, the computed sample size works out to be 352 .

\section{Inclusion criteria}

Patient's age 18 and above of both genders. Relatively stable patients were included in the study. The patient selection was random and the diseases that were included were: chronic obstructive pulmonary disease, asthma, bronchiectasis and ILD.

Patients who were on treatment for a period ranging from 1 month to 12 months who were willing to participate and sign the informed consent form, were included.

A specially designed case record form (CRF) was used to record case details which include patient details (demographic details): patient number, patient initials, age, sex, date, diagnosis, relevant investigations (if any) along with routine physical examination.

The ADR information was collected personally after interviewing subjects/caregivers. The details of ADR which were present at the time of visit or occurred within one month (to avoid recall bias) were noted in the ADR reporting Form. Based on the outcome of modified Hartwig and Siegel severity assessment scale, ADRs were grouped into various severity category and their percentage values were calculated.

Data were analyzed by using Microsoft excel sheet. All results have been expressed in percentage frequencies. Fisher's exact (2 tailed) test was used as a test of significance where expected numbers in a cell is <5. If expected number in a cell is $>5$, Pearson's chi square test was used as a test of significance.

\section{RESULTS}

\section{Demographic data analysis}

A total of 352 patients were enrolled in the study. Out of this $211(59.9 \%)$ were male and $141(40.1 \%)$ were female. (Table 1).

When the range of age of the patients was calculated it was found to be $18-73$ years. The mean age of the population 
was $46.39 \pm 8.6$ years. Maximum no. of patients were in the age group of 51-60 years i.e., 90 followed by 41-50 years i.e., 76 (Table 2).

Table 1: Gender-wise distribution in the study population, $(\mathrm{n}=352)$.

\begin{tabular}{|lll|}
\hline Gender & No. of patients & Percentage (\%) \\
\hline Male & 211 & 59.9 \\
\hline Female & 141 & 40.1 \\
\hline Total & 352 & 100 \\
\hline
\end{tabular}

The number of COPD patients were maximum to be 167 $(47.44 \%)$, followed by asthma $78(22.16 \%)$, bronchiectasis
$69(19.60 \%)$ and ILD $38(10.80 \%)$ (Table 5).

Table 2: Age wise distribution in study population, $(n=352)$.

\begin{tabular}{|lll|}
\hline Age (years) & No. of patients & Percentage $(\%)$ \\
\hline $\mathbf{1 8 - 3 0}$ & 65 & 18.46 \\
\hline $\mathbf{3 1 - 4 0}$ & 54 & 15.34 \\
\hline $\mathbf{4 1 - 5 0}$ & 76 & 21.59 \\
\hline $\mathbf{5 1 - 6 0}$ & 90 & 25.57 \\
\hline $\mathbf{> 6 0}$ & 67 & 19.04 \\
\hline Total & 352 & 100 \\
\hline
\end{tabular}

Table 3: Drug profile in the study population.

\begin{tabular}{|c|c|c|c|c|}
\hline Class of drug & Name of drug & Number & $\begin{array}{l}\text { No. of } \\
\text { patients }\end{array}$ & $\begin{array}{l}\text { Percentage of } \\
\text { population }(\%)\end{array}$ \\
\hline \multirow{3}{*}{ Beta agonists (BA) } & Formoterol & 170 & \multirow{3}{*}{288} & \multirow{3}{*}{81.82} \\
\hline & Salmeterol & 70 & & \\
\hline & Levosalbutamol & 48 & & \\
\hline \multirow{3}{*}{ Anticholinergics (AC) } & Tiotropium & 108 & \multirow{3}{*}{153} & \multirow{3}{*}{43.47} \\
\hline & Ipratropium & 30 & & \\
\hline & Glycopyrronium & 15 & & \\
\hline Methylxanthines (MX) & Theophylline & 118 & 118 & 33.52 \\
\hline \multirow{2}{*}{ Corticosteroids (CS) } & Budesonide & 125 & \multirow{2}{*}{195} & \multirow{2}{*}{55.40} \\
\hline & Fluticasone & 70 & & \\
\hline Cough expectorants (CE) & Guaifenesin & 57 & 57 & 16.19 \\
\hline Mucolytic (ML) & $\mathrm{N}$ acetyl cysteine & 58 & 58 & 16.48 \\
\hline Leukotriene antagonists (LA) & Montelukast & 15 & 15 & 4.26 \\
\hline Immunosuppressants (IS) & Azathioprine & 29 & 29 & 8.24 \\
\hline Antifibrotic (AF) & Pirfenidone & 38 & 38 & 10.80 \\
\hline Antitussives (AT) & Dextromethorphan & 12 & 12 & 3.41 \\
\hline
\end{tabular}

There was total 10 classes of drugs prescribed in study population: beta agonists, anticholinergics, methylxanthines, corticosteroids, mucolytics, cough expectorants, leukotriene antagonists, immunosuppressants, antifibrotic agent and antitussives (Table 3).

\section{Adverse drug reaction profile}

132 adverse drug reactions (ADRs) were seen in 69 out of 352 patients $(19.6 \%)$ of the study population. The occurrence of adverse drug reaction was found the slightly higher in males i.e., $53.62 \%$ as compared to females i.e., $45.38 \%$ as shown in the Table 4.

The patients who were on treatment for ILD showed highest percentage of ADRs i.e., 57.89\% which is followed by bronchiectasis $(17.39 \%)$, chronic obstructive pulmonary disease $(16.17 \%)$ and lastly asthma (10.26\%) (Table 5).
Table 4: Age and gender wise distribution of ADR cases.

\begin{tabular}{|llll|}
$\begin{array}{l}\text { Age } \\
\text { (years) }\end{array}$ & Male & Female & $\begin{array}{l}\text { Total } \\
\text { percentage } \\
(\%)\end{array}$ \\
\hline $\mathbf{1 8 - 3 0}$ & $4(5.80)$ & $2(2.90)$ & $6(8.70)$ \\
\hline $\mathbf{3 1 - 4 0}$ & $5(7.25)$ & $1(1.45)$ & $6(8.70)$ \\
\hline $\mathbf{4 1 - 5 0}$ & $3(4.35)$ & $11(15.94)$ & $14(20.29)$ \\
\hline $\mathbf{5 1 - 6 0}$ & $13(18.84)$ & $13(18.84)$ & $26(37.68)$ \\
\hline$>$ 60 & $12(17.38)$ & $5(7.25)$ & $17(24.63)$ \\
\hline Total & $37(53.62)$ & $32(46.38)$ & $69(100)$ \\
\hline
\end{tabular}

Among the 69 patients who showed adverse drug reactions, 22 patients $(31.88 \%)$ showed single adverse drug reaction, $33(47.83 \%)$ showed two adverse drug reactions, $12(17.39 \%)$ showed three adverse drug reactions and two $(2.90 \%)$ showed four adverse drug reactions. 
Table 5: Disease wise incidence of ADR in the study population.

\begin{tabular}{|lllll|}
\hline Disease & No. of patients & $\begin{array}{l}\text { No. of patients } \\
\text { with ADRs }\end{array}$ & $\begin{array}{l}\text { Percentage of patients with } \\
\text { ADRs }(\%)\end{array}$ & No. of ADRs \\
\hline COPD & 167 & 27 & 16.17 & 47 \\
\hline Asthma & 78 & 8 & 10.26 & 14 \\
\hline Bronchiectasis & 69 & 12 & 17.39 & 21 \\
\hline ILD & 38 & 22 & 57.89 & 50 \\
\hline Total & 352 & 69 & - & 132 \\
\hline
\end{tabular}

It is evident from the study, that the ADRs belonging to GIT system were highest in number i.e., 80. The most common GIT system related ADR was epigastric discomfort occurring in 13 cases out of 69 i.e., $18.84 \%$ of the ADR positive population. Most common ADR in CNS system was headache occurring in 7 cases i.e., $10.14 \%$. The most frequently occurring ADR in study was palpitation which occurred in 14 cases, 20.29\% (Table 6).

Table 6: System wise distribution of ADRs.

\begin{tabular}{|llll|}
\hline $\begin{array}{l}\text { Body system } \\
\text { Gastrointestinal system (80) }\end{array}$ & No. of ADR & $\begin{array}{l}\text { Percentage out of total } \\
\text { ADRs }(\%)\end{array}$ & $\begin{array}{l}\text { ADR present } \\
\text { population (\%) }\end{array}$ \\
\hline Nausea & 10 & 7.58 & 14.49 \\
\hline Vomiting & 4 & 3.03 & 5.80 \\
\hline Loss of appetite & 4 & 3.03 & 5.80 \\
\hline Altered taste & 3 & 2.27 & 4.35 \\
\hline Constipation & 5 & 3.79 & 7.25 \\
\hline Diarrhoea & 3 & 2.27 & 4.35 \\
\hline Dryness of mouth & 10 & 7.58 & 14.49 \\
\hline Thirst & 7 & 5.30 & 10.14 \\
\hline Bitter taste & 11 & 8.33 & 15.94 \\
\hline Epigastric discomfort & 13 & 9.85 & 18.84 \\
\hline Abdominal pain & 8 & 6.06 & 11.59 \\
\hline Aphthous ulcer & 2 & 1.52 & 2.90 \\
\hline Central nervous system $(\mathbf{1 7})$ & & & 4.35 \\
\hline Tremor & 3 & 2.27 & 10.14 \\
\hline Headache & 7 & 5.30 & 4.35 \\
\hline Insomnia & 3 & 2.27 & 5.80 \\
\hline Sedation & 4 & 3.03 & 20.29 \\
\hline Others (35) & & & 13.04 \\
\hline Palpitation & 14 & 10.60 & 4.35 \\
\hline Sore throat & 9 & 6.82 & 2.90 \\
\hline Oral candidiasis & 3 & 2.27 & 7.25 \\
\hline Icterus & 2 & 1.52 & 2.90 \\
\hline Body ache & 5 & 3.79 & - \\
\hline Muscle pain & 2 & 1.52 & \\
\hline Total & 132 & 100 & \\
\hline
\end{tabular}

According to modified Hartwig and Siegel severity assessment scale, the adverse drug reactions were classified. Out of 132 adverse drug reactions observed, 96 i.e., $72.73 \%$ belonged to the mild category and 36 adverse drug reactions i.e., $27.27 \%$ belonged to the moderate category. Not a single severe adverse drug reaction was found in the study (Table 7).

\section{Drug ADR profile}

Out of 132 ADRs found, there were total 80 GIT ADRs in which maximum number of patients were being treated by beta agonists i.e., 49, f/b mucolytics i.e., 39 and least by antitussives i.e., 10 (Table $8 \mathrm{~A})$.

Table 7: Classification of ADRs according to severity.

\begin{tabular}{|ll|l|}
\hline Grade of ADR & No. of ADR & Percentage (\%) \\
\hline Mild & 96 & 72.73 \\
\hline Moderate & 36 & 27.27 \\
\hline Severe & 0 & 0 \\
\hline Total & 132 & 100 \\
\hline
\end{tabular}


There were total 17 CNS ADRs in which maximum number of patients were being treated by beta agonists i.e., $15 \mathrm{f} / \mathrm{b}$ methylxanthines and steroids i.e., 13 (Table 8B).
When analysed for other ADRs affecting different parts of the body, it was found that palpitation was common and drugs responsible for it were from beta agonist class i.e., in 14 patients receiving BA complained palpitation. Other ADRs very less in number (Table $8 \mathrm{C}$ ).

Table 8A: Number of patients with GIT ADRs with different classes of drugs.

\begin{tabular}{|c|c|c|c|c|c|c|c|c|c|}
\hline GIT & $\mathbf{B A}$ & $\mathbf{A C}$ & MX & $\mathbf{S}$ & $\mathbf{C E}$ & ML & IS & $\mathbf{A F}$ & AT \\
\hline Nausea & 4 & 1 & 1 & 4 & 1 & 9 & 7 & 9 & 2 \\
\hline Vomiting & 1 & 0 & 0 & 1 & 0 & 4 & 4 & 4 & 0 \\
\hline Loss of appetite & 4 & 0 & 0 & 4 & 2 & 4 & 0 & 4 & 2 \\
\hline Altered taste & 3 & 1 & 0 & 3 & 2 & 0 & 0 & 0 & 0 \\
\hline Constipation & 3 & 4 & 1 & 1 & 0 & 0 & 0 & 0 & 0 \\
\hline Diarrhoea & 0 & 0 & 0 & 0 & 0 & 3 & 3 & 3 & 0 \\
\hline Dryness of mouth & 6 & 10 & 0 & 0 & 0 & 3 & 0 & 0 & 0 \\
\hline Thirst & 5 & 7 & 0 & 0 & 0 & 3 & 0 & 0 & 0 \\
\hline Bitter taste & 8 & 8 & 2 & 3 & 0 & 4 & 1 & 1 & 0 \\
\hline Epigastric discomfort & 9 & 1 & 7 & 8 & 4 & 4 & 5 & 7 & 3 \\
\hline Abdominal pain & 5 & 0 & 4 & 5 & 2 & 4 & 5 & 6 & 2 \\
\hline Aphthous ulcer & 1 & 0 & 1 & 1 & 0 & 1 & 2 & 2 & 1 \\
\hline Total & 49 & 32 & 16 & 30 & 11 & 39 & 27 & 36 & 10 \\
\hline
\end{tabular}

Table 8B: Number of patients with CNS ADRs with different classes of drugs.

\begin{tabular}{|llllllllll|}
\hline CNS & BA & AC & MX & S & CE & ML & IS & AF & AT \\
\hline Tremor & 3 & 1 & 2 & 2 & 0 & 1 & 0 & 0 & 0 \\
\hline Headache & 7 & 0 & 5 & 6 & 1 & 0 & 0 & 0 & 0 \\
\hline Insomnia & 3 & 0 & 3 & 3 & 0 & 0 & 0 & 0 & 0 \\
\hline Sedation & 2 & 0 & 3 & 2 & 2 & 1 & 2 & 2 & 2 \\
\hline Total & 15 & 1 & 13 & 13 & 3 & 2 & 2 & 2 & 2 \\
\hline
\end{tabular}

Table 8C: Number of patients with other ADRs with different classes of drugs.

\begin{tabular}{|llllllllll|}
\hline Others & BA & AC & MX & S & CE & ML & IS & AF & AT \\
\hline Palpitation & 14 & 1 & 10 & 12 & 3 & 2 & 1 & 1 & 0 \\
\hline Sore throat & 9 & 0 & 0 & 9 & 5 & 1 & 0 & 1 & 1 \\
\hline Oral candidiasis & 3 & 0 & 1 & 3 & 0 & 1 & 1 & 1 & 0 \\
\hline Icterus & 0 & 0 & 1 & 0 & 0 & 1 & 2 & 2 & 1 \\
\hline Body ache & 2 & 0 & 2 & 2 & 1 & 3 & 5 & 5 & 2 \\
\hline Muscle pain & 1 & 0 & 1 & 1 & 1 & 1 & 2 & 2 & 0 \\
\hline Total & 29 & 1 & 15 & 27 & 10 & 9 & 11 & 12 & 4 \\
\hline
\end{tabular}

Table 9: Drugs prescribed in patients having ADRs (Total 69 patients).

\begin{tabular}{|lll|}
\hline Class of drug & $\begin{array}{l}\text { No. of patients receiving it } \\
\text { (out of } \mathbf{6 9})\end{array}$ & $\begin{array}{l}\text { Percentage of ADR positive } \\
\text { population receiving it (\%) }\end{array}$ \\
\hline Beta agonists & 54 & 78.26 \\
\hline Anticholinergics & 15 & 21.74 \\
\hline Methylxanthines & 27 & 39.13 \\
\hline Corticosteroids & 43 & 62.32 \\
\hline Cough expectorants & 16 & 23.19 \\
\hline Mucolytics & 23 & 33.33 \\
\hline Immunosuppressants & 17 & 24.64 \\
\hline Pirfenidone & 22 & 31.88 \\
\hline Antitussives & 7 & 10.14 \\
\hline
\end{tabular}


Table 10: General profile of the drug treatment and ADRs.

\begin{tabular}{|llll|}
\hline Class of drug & $\begin{array}{l}\text { No. of patients } \\
\text { receiving drug }\end{array}$ & $\begin{array}{l}\text { No. of patients complaining } \\
\text { ADRs }\end{array}$ & \begin{tabular}{l} 
Incidence $(\%)$ \\
\hline Beta agonists (BA)
\end{tabular} \\
\hline Anticholinergics (AC) & 288 & 54 & 18.75 \\
\hline Methylxanthines (MX) & 153 & 15 & 22.80 \\
\hline Corticosteroids (CS) & 118 & 27 & 22.05 \\
\hline Mucolytic (ML) & 58 & 43 & 39.66 \\
\hline Cough expectorants (CE) & 57 & 23 & 28.07 \\
\hline Immunosuppressants (IS) & 29 & 16 & 58.62 \\
\hline Antifibrotic (AF) & 38 & 22 & 57.89 \\
\hline Antitussives (AT) & 12 & 7 & 58.33 \\
\hline
\end{tabular}

The drug utilisation pattern of different classes of drugs in patients positive for ADRs i.e., 69 patients; shows that 54 of them i.e., $78.26 \%$ received beta agonists, followed by corticosteroids in 43 patients i.e., $62.32 \%$ (Table 9).

It was seen that immunosuppressants with $58.62 \%$, antitussives with $58.33 \%$ and antifibrotic agent with $57.89 \%$ incidence of ADRs with their use were the top 3 most ADR associated classes of drugs. Anticholinergics were associated with the least number of patients with ADRs, i.e., 15 cases (9.8\%) (Table 10).

\section{DISCUSSION}

Chronic non-infective respiratory diseases are very important health problems worldwide. With the advent of new treatment options, entirely new concerns regarding different patterns of ADR and drug interactions have arisen. It places a substantial stress on limited healthcare resources and has considerable negative impact on both health and healthcare costs by affecting patient's recovery. ${ }^{7}$

In our study, we enrolled 352 patients of CNIRD diagnosed by chest physician of our tertiary care institute. This study was conducted after taking approval from the institutional ethics committee. In our study mainly the patients of COPD, Asthma, Bronchiectasis and ILD were enrolled after fulfilling the selection criteria.

The main aim of the study was to monitor different ADRs in this population of patients who are treated by different classes of drugs. At the same, we tried to find out the burden of ADRs in these patients, the association of ADRs with different drugs and overall picture of drug-ADR profile.

\section{Demographic profile of the study population}

When the overall 352 patients were analyzed for their demographic parameters like age, gender etc. it was found that a maximum number of patients were from 51-60 age group i.e., $25.57 \%$ f/b $41-50$ years i.e., $21.59 \%$. The mean age of the sample was $46.39 \pm 8.6$ years while there were patients from age of 18 to 73 years. In a similar study carried out by Petrova et al majority of the patients i.e., $75 \%$ were found beyond 61 years of age $\mathrm{f} / \mathrm{b}$ in the age group 51-60 years $(18.16 \%) .{ }^{8}$ Oltmanns et al carried out a similar study where again the findings were in contrast to our findings. They found that the majority of their study population was in the age group of $7^{\text {th }}$ and $8^{\text {th }}$ decade of life i.e., $68 \pm 7$ years. $^{9}$

Studying the gender distribution reveals that $59.9 \%$ males and $40.1 \%$ females were enrolled in our study which was in contrast to studies conducted by Oltmanns et al where they enrolled 63 patients in which 47 males $(75 \%)$ and 16 females $(25 \%)$ were present. Tyagi et al carried out a study where 60 patients were enrolled in which 56 males $(93.33 \%)$ and 4 females $(6.67 \%)$ were present. $^{3}$

\section{Drug profile}

Among all the drugs, beta agonist drugs were majorly prescribed in $81.82 \%$ patients $\mathrm{f} / \mathrm{b}$ steroids in $55.40 \%$ patients and in anti-cholinergics drugs were prescribed in $43.47 \%$. Our findings of the use of drugs match with the study conducted by Tyagi et al where beta agonists were used in maximum number of patients $\mathrm{f} / \mathrm{b}$ inhaled steroids and anti-cholinergics with theophylline on $4^{\text {th }}$ number. ${ }^{3}$

\section{ADR profile}

In the ADR profile, we found out that out of 352 patients, there were 69 patients (19.6\%) who presented with ADRs. In an open and non-comparative study, by Jamali et al inasthma patients, 200 patients were enrolled in the study. ${ }^{10,13}$ out of 200 i.e., $6.5 \%$ of the patient population were positive for ADR which was less compared to the findings of our study. ${ }^{10}$

In our study, in ILD 22 out of 38 i.e., $57.89 \%$ patients were positive for ADR which was the highest percentage in our study. The study done by Oltmanns et al in patients of ILD also showed that 52 out of 63 patients i.e., $85 \%$ of the study population was affected with ADRs. ${ }^{9}$ Use of immunosuppressive drugs like azathioprine and pirfenidone (antifibrotic agent) might have contributed to this finding.

Majority of the patients i.e., $47.83 \%$ had two ADRs, f/b single ADR in $31.88 \%$, three ADRs in $17.39 \%$ and four 
ADRs in $2.9 \%$ of the ADR positive population. This made a total of 132 ADRs belonging to various systems of the body.

Gender wise distribution of ADR positive population shows that $53.62 \%$ males and $46.38 \%$ females were affected in our study. This was in contrary to the findings of two studies by Jamali et al and Bhosale et al where the incidence of ADRs was more in females as compared to males. ${ }^{10,11}$

When age wise distribution of ADRs was calculated, it was found that highest number of patients i.e., $37.68 \%$ were seen in the age group of 51-60 years $\mathrm{f} / \mathrm{b}>60$ years i.e., $24.63 \%$. A study by Bhosale et al reveals that their highest number of the ADR positive patients i.e., $45.5 \%$ belonged to 31-40 years of age group $\mathrm{f} / \mathrm{b}$ 21-30 years and 41-50 years with $18.1 \%$ each. ${ }^{11}$ Another study by Jamali et al shows that the highest number of patients were affected in the age group of 41-50 years i.e., $46.7 \% \mathrm{f} / \mathrm{b} 31-40$ years i.e., $26.7 \% .^{10}$

After system wise distribution of ADRs in our study, it was evident that gastrointestinal (GIT) system was most commonly affected system with $60.61 \%$ ADRs, f/b central nervous system (CNS) with $12.88 \%$ ADRs. Remaining other ADRs belonging to the various system of body constituted $26.51 \%$ of ADRs. This was in agreement with the study conducted by Oltmanns et al and Jiang et al who also found that GIT was the most common system affected in their study. ${ }^{9,12}$ On the contrary, Petrova et al experienced that in their study, the highest number of ADRs belonged to CNS, f/b respiratory system (RS), GIT and cardiovascular system (CVS). ${ }^{8}$

We classified 132 ADRs in our study on the basis of severity using modified Hartwig and Siegel severity assessment scale. ${ }^{13} 72.73 \%$ ADRs belonged to the mild category and $27.27 \%$ ADRs belonged to the moderate category. Not a single severe ADR was found in the study. This finding was closely related to the findings of the two studies conducted by Bhosale et al and Jamali et al where only mild and moderate categories of ADRs were detected and no severe ADR was reported. ${ }^{10,11}$ However it was in contrast to studies conducted by Tyagi and Petrova et al where serious ADRs were reported..$^{3,8}$

\section{Drug ADR profile}

When tried to find out the association between drugs and ADRs in the study population. Of the 10 classes of drugs used in the study, all except leukotriene antagonists, showed ADRs. This is supported by the study done by Bhosale et al where no ADR was reported with the use of leukotriene antagonist. ${ }^{11}$ On the contrary, a study by Jamali et al suggests that maximum percentage of ADRs in their study population was found to be associated with Montelukast, a leukotriene antagonist. ${ }^{10}$

Out of the total 352 patients, 69 patients who showed
ADRs, maximum patients were receiving beta agonist drugs i.e., 54 patients $(78.26 \%) \mathrm{f} / \mathrm{b}$ steroids in 43 patients (62.32\%), methylxanthines in 27 patients (39.13), mucolytics in 23 patients $(33.33 \%)$, pirfenidone in 22 patients $(31.88 \%)$, immunosuppressants in 17 patients (24.64), cough expectorants in 16 patients (23.19\%), anticholinergic in 15 patients $(21.74 \%)$ and antitussives in 7 patients $(10.14 \%)$.

For calculating significance of association between drug and ADR, 2x2 contingency tables were made for each class of drug, using data whether and in what number the drug was given to patients who are positive for ADRs. Fisher's exact (2 tailed) test was used as a test of significance where expected numbers in a cell is $<5$. If expected number in a cell is $>5$, Pearson's chi-square test was used as a test of significance. Odds ratio and $95 \%$ confidence intervals were calculated for $2 \times 2$ ADR tables. It was seen that classes of drugs which had a positive significant association with ADR positive patients areimmunosuppressants, antifibrotic agent, mucolytics, antitussives and corticosteroids.

\section{Limitations}

As all the patients monitored in our study were on multidrug therapy, and many patients showed multiple ADRs, the various ADRS could not be clearly attributed to any specific drug. Also, we tried to find out the significant association of each ADR with each class of drug. But since the values in almost all the $2 \times 2$ contingency tables were less than 5 , it was not possible to establish significance statistically.

\section{CONCLUSION}

From our study, the following conclusions can be drawn: Out of 352 enrolled patients, 69 patients presented with ADRs and total ADRs found in this population were 132. Gastrointestinal system was the most commonly affected system by different drugs with epigastric discomfort being the most common presenting complaint in this system. Beta agonist was the most commonly prescribed class of drugs to these patients. The highest percentage of ADR was seen in patients of ILD f/b COPD. Percentage of occurrence of ADRs was most commonly seen in patients on treatment with immunosuppressant, antifibrotic and antitussive drugs. Majority ADRs were mild to moderate in nature with no occurrence of severe ADR.

It is important to establish information management systems to detect and report adverse drug events in chronic non-infective respiratory diseases treatment. The focus should be given on assessment and prevention of medication errors resulting in adverse drug reactions. Also, many further studies should be conducted for a longer period of time, in a larger sample, in diverse communities with various variables for better results and establishment of data. 


\section{ACKNOWLEDGEMENTS}

Author would like to thanks to Dr. Ranjit Mankeshwar (Professor, department of PSM, GGMC and Sir JJ group of hospitals) for his valuable guidance during the study project.

Funding: No funding sources

Conflict of interest: None declared

Ethical approval: The study was approved by the Institutional Ethics Committee

\section{REFERENCES}

1. Burney P, Jarvis D, Perez-Padilla R. The global burden of chronic respiratory disease in adults. Int $\mathrm{J}$ Tuberculosis Lung Dis. 2015;19(1):10-20.

2. Khan A, Adil MS, Nematullah K, Ihtisham S, Aamer $\mathrm{K}$.ASC assessment of adverse drug reaction in PD of a TCHJBCP. 2015;6(3):84-8.

3. Tyagi N, Gulati K, Vijayan VK, Ray A. A study to monitor adverse drug reactions in patients of chronic obstructive pulmonary disease: Focus on theophylline. Indian $\mathrm{j}$ chest dis allied sci. 2008;50(2):199.

4. Geneva: World Health organization. Requirements for adverse drug reaction reporting. 1975;1039-109.

5. Lazarou J, Pomeranz BH, Corey PN. Incidence of adverse drug reactions in hospitalized patients: A meta-analysis of prospective studies. JAMA. 1998;279:1200-5.

6. Ohta K, Fukuchi Y, Grouse L, Mizutani R, Rabe KF, Rennard SI et al. A prospective clinical study of theophylline safety in 3810 elderly with asthma or COPD. Respir Med. 2004;98:1016-24.

7. Shamna M, Dilip C, Ajmal M, Linu PM, Shinu C, Jafer CP. A prospective study on Adverse Drug
Reactions of antibiotics in a tertiary care hospital. Yahiya Mohammed b. Saudi Pharmaceutical J. 2013;12:30-3.

8. Petrova G, Stoimenova A, Dimitrova M, Kamusheva M, Petrova D, Georgiev O. Assessment of the expectancy, seriousness and severity of adverse drug reactions reported for chronic obstructive pulmonary disease therapy. SAGE open medicine. 2017;5:205031.

9. Oltmanns U, Kahn N, Palmowski K, Träger A, Wenz $\mathrm{H}$, Heussel $\mathrm{C}$ et al. Pirfenidone in Idiopathic Pulmonary Fibrosis: Real-Life Experience from a German Tertiary Referral Center for Interstitial Lung Diseases. Respiration. 2014;88(3):199-207.

10. Jamali AN, Aqil M, Alam MS, Pillai KK, Kapur P. A pharmacovigilance study on patients of bronchial asthma in a teaching hospital. J Pharm Bioallied Sci. 2010;2(4):333-6.

11. Bhosale U, Jaiswal S, Yegnanarayan R, Godbole G. A pharmacovigilance study of antiasthmatic agents in patients of bronchial asthma at a tertiary care hospital. J Clin Exp Res. 2013;1(2):26.

12. Jiang C, Huang H, Liu J, Wang Y, Lu Z, Xu Z. Adverse Events of Pirfenidone for the Treatment of Pulmonary Fibrosis: A Meta-Analysis of Randomized Controlled Trials. PLoS ONE. 2012;7(10):e47024.

13. Hartwig SC, Siegel J, Schneider PJ. Preventability and severity assessment in reporting adverse drug reactions. Am J Heal Pharm. 1992;49(9):2229-32.

Cite this article as: Gaidhane SS, Khobragade AA, Joshi A, Chavan MS, Likith HV, Chaware AA. A pharmacovigilance study in patients of chronic noninfective respiratory diseases attending outpatient department of pulmonary medicine in a tertiary care teaching hospital. Int J Basic Clin Pharmacol 2021;10:675-85. 